Acta Poetica 25-1

PRIMAVERA

2004

\title{
Entre ética y poética: heteronomías meridionales
}

\author{
Silvana Rabinovich
}

El presente texto trata de aproximarse a la relación entre la ética de Emmanuel Levinas y la poesía de Paul Celan. La conferencia del poeta a la que se alude, pronunciada con motivo de la recepción del premio Georg Büchner en octubre de 1960, se titula "El meridiano", y en su densa trama - entre muchas otras cuestiones - expone la poesía desde una perspectiva dialógica. El filósofo de la alteridad, por su parte, —a diferencia de la tradición filosófica que vio durante siglos en el problema del ser su tarea fundamental (y la moral autónoma como una consecuencia de la pregunta ontológica)_, asume la precedencia y prelación de la relación con los otros, proponiendo a la ética - heterónoma - como filosofía primera. La ética y la poética se rozan: en sus orígenes griegos, la poesía es acto de la palabra, la ética por su parte es filosofía práctica. A partir de la lectura de estos autores cada uno, a su manera, testimonia acerca del encuentro con el otro, de un momento en que el sujeto despierta de la prolongada ensoñación monológica. A lo largo de este trabajo, la polisemia que recorre al significante "meridiano" dará lugar al acercamiento de estas formas del pensamiento.

This text is an attempt to approach the relationship between Emmanuel Levinas' ethics and Paul Celan's poetry. The poet's conference referred to, which took place at the ceremony where he received the Georg Büchner award in October 1960, is called "The Meridian", and in its complex plot, among many other issues, he looks at poetry from a dialogic perspective. The philosopher of alterity - contrary to the philosophical tradition that for centuries considered the problem of being as its fundamental task (and the autonomous moral as a consequence of the ontological question)_, assumes the precedence and prelation of the relationship with the others, claiming heteronomous ethics as first 
philosophy. Ethics and poetics lie close together: in its Greek origin, poetry is the act of the word, and ethics is practical philosophy. The reading of these authors evidences the encounter with the other, each one in his own way. It is a moment in which the individual awakes from a long monologic dream. Throughout this paper, the polisemy present in the significant "meridian" will enable the approach to these forms of thinking.

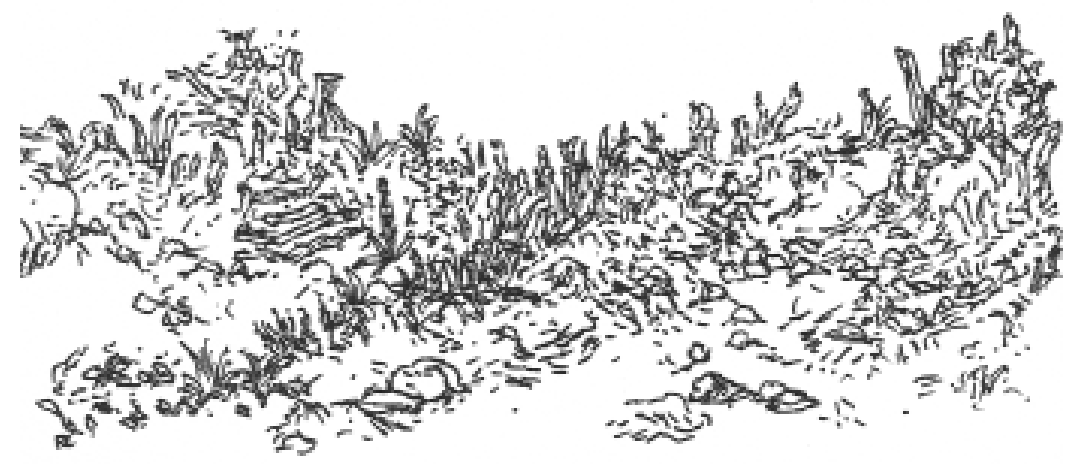


Acta Poetica 25-1

PRIMAVERA

2004

Silvana Rabinovich

\section{Entre ética y poética: heteronomías meridionales}

“...Ese es mi lugar bajo el sol”.

He aquí el comienzo y la imagen de la usurpación de toda la tierra.

Pascal, Pensées ${ }^{1}$

Bajo el sol, al mediodía, sin sombras, sin coartada: la perspectiva meridional, exige ponerse "de cabeza" y así mirar de otro modo:

El que anda con la cabeza (...) tiene el cielo como abismo bajo sus pies. ${ }^{2}$

En otras palabras: nos proponemos pensar la ética desde la exterioridad de la heteronomía y no desde la tradicional autonomía; o en palabras poéticas: con el infinito abismal como base. Con las debidas resonancias de la conferencia de Paul Celan citada, abordaremos la responsabilidad heterónoma desde la noción de Meridiano. Levinas —el filósofo- y Celan —el poeta-, harán posible la aproximación a la cuestión del otro desde una luz meridiana. Bajo el sol del mediodía, la usurpación alu-

\footnotetext{
${ }^{1}$ Citado por Levinas en De otro modo que ser, 8.

2 Celan, "El Meridiano". Discurso con motivo de la concesión del premio Georg Büchner, Darmstadt, 22 de octubre de 1960, en Obras completas, 504.
} 
dida en la reflexión de Pascal es insoslayable. El poema como memoria del nomadismo, cuestiona la ocupación y obliga a ponerse en camino. Trataremos entonces, a partir de la conferencia de Celan y de la lectura que de ésta hace Levinas, de explorar algunas proyecciones éticas de la poesía (así como también del componente poético que atraviesa a la ética heterónoma).

\section{Del poema al otro: un Meridiano}

El poema quiere ir hacia algo Otro, necesita ese Otro, necesita un interlocutor. Se lo busca, se asigna.

Cada cosa, cada hombre es para el poema que mantiene el rumbo hacia ese Otro una forma de ese Otro. ${ }^{3}$

Paul Celan, en su conferencia "El Meridiano", sostiene -contrariamente a la teoría del "arte monológico"_— que el poema absoluto — dirigido a nadie — no existe, que siempre se escribe para Otro. Aclaremos que no se trata de dedicar el poema a un destinatario definido, sino que es un intento de aproximarse a la alteridad constitutiva del sujeto, en su relación de sujeción con el Otro. Sujeto sujetado a la responsabilidad inmemorial es el que rescata el filósofo, sujeto al Otro se encuentra el poeta —en tanto que da la palabra-. La pasividad se dice a dos voces: la voz filosófica invoca a la frágil subjetividad que se estremece ante la interpelación del otro, la voz del poeta se sabe escucha, médium. En ambos resuena la dimensión profética de la palabra: ${ }^{5}$ la escucha precede a la palabra dada al otro como

\footnotetext{
${ }^{3}$ Celan, 506.

${ }^{4}$ La referencia es a Gottfried Benn, citado por Rafael Gutiérrez Girardot en "Poesía del silencio", 24. Por supuesto también a Mallarmé.

5 Debe aclararse el término "profético" que no alude al don de predecir el futuro, sino a la capacidad de algunos individuos de prestar la boca para recibir y proferir la palabra del Otro. En el Fedro, Platón elogia cuatro clases de locura: la profética, la poética, la mistérica y la erótica. La primera concierne a Apolo, la
} 
respuesta ante la solicitación, el poeta aguza el oído y en el estremecimiento de la inspiración, profiere el poema. Se trata de un Decir que es primeramente escucha y no emisión de un mensaje por decodificar. Tampoco es una entidad abstracta como la lengua quien habla, lejos de toda neutralidad o abstracción, alguien habla y su palabra es una interpelación, y a su vez es respuesta comprometida con la interpelación de otro. A tientas, el poema profiere una palabra que espera ser escuchada en la otra orilla para acariciar el sentido, y a la vez para solicitar a quien escucha. El poeta no posee el significado, sino que sale en busca del sentido, de otra dirección, una salida hacia el Otro, hacia la intemperie en que se da el encuentro. El poema, por eso, está en camino, nos pone en camino:

Puesto que es una manifestación del lenguaje y por tanto esencialmente dialógico, el poema puede ser una botella de mensaje lanzada con la confianza - ciertamente no siempre muy esperanzadora— de que pueda ser arrojada a tierra en algún lugar y en algún momento, tal vez a la tierra del corazón. De igual forma, los poemas están en camino: rumbo hacia algo.

¿Hacia qué? Hacia algo abierto, ocupable, tal vez hacia un tú asequible, hacia una realidad asequible de la palabra. ${ }^{6}$

Palabras ambiguas que reflejan en la escritura una "confianza — ciertamente no siempre muy esperanzadora"- No se trata de dialogismo optimista pero tampoco de un pesimismo hermético de poesía autorreferente, el poeta es testigo de una lengua que después de Auschwitz (y en lo que resuena de ese nombre en otras latitudes y tiempos) se encuentra en estado de cenizas. (Esa lengua — que también es política y "tiene su 20 de enero" -7 no logra rehabilitarse porque estas

segunda a las Musas, la tercera a Dionisos y la cuarta a Eros: todas se consideran dones y no falta de razón.

6 Celan, "Discurso de Bremen", en Obras completas, 497-498.

${ }^{7}$ Cf. A propósito del Lenz de Büchner, el poeta rumano habla de fechas que como el tiempo "atraviesan" el poema, una eternidad que como una flecha pasa $a$ 
cenizas se sedimentaron en gruesas capas eufemísticas: las palabras presionan como lava ardiente por recuperar algo de su poder explosivo, ellas todavía pueden decir mucho más que lo que sus detentadores quieren decir). La poesía, entonces, anuncia la palabra por venir, y en este sentido es "contrapalabra", invoca a lo inaudito:

¡Pero el poema habla! Recuerda sus fechas, habla (...) habla en nombre de la causa de eso Otro, quién sabe si de un otro totalmente Otro. ${ }^{8}$

El poema se hace camino en una delgada línea que (al modo talmúdico), no teme transitar esa tierra de nadie que es la coexistencia de lo contradictorio. La dirección es "tal vez" hacia lo asequible (la palabra, el tú) pero a la vez hacia la inasible alteridad. El poema es dialógico por su capacidad de escuchar lo otro, de preguntar y de compartir perplejidades, o de volverse eco de algo que perturba, de eso "otro, totalmente Otro". Hay un poeta que refiere a aquello inasible que perturba:

L'insaisissable — l'invisible — perturbent, parfois, au-delà du tolérable. ${ }^{9}$

Lo invisible perturba, dice Jabès; sin embargo, podemos pensar también —desde esta perspectiva meridional o heterónoma-, que aquello que perturba por ser inasible - no tolerado- en nuestro "orden" es invisibilizado. El poema - la contrapalabra que es eco de lo inasible — lanzado por las aguas

través del tiempo, pero sin pasarlo por encima. Fechas como el 20 de enero (en el caso de Celan, se trata del año 1942, en que tuvo lugar la reunión de Wannsee, en la que se llegó al acuerdo de la "Solución Final", esto es, de la exterminación de los judíos de Europa) son flechas envenenadas en la memoria de la humanidad.

${ }^{8}$ Celan, 505.

9 Jabès, Le Parcours, 103: — "Lo inasible —lo invisible— perturban, a veces, más allá de lo tolerable" (traducción de S. R.). 
del lenguaje, da cuenta de la responsabilidad que nos concierne en este proceso de invisibilización, que es el esfuerzo recurrente por suprimir al otro. El diálogo "desesperado" al que refiere Celan, roza aquello que se encuentra "más allá de lo tolerable":

El poema se convierte — ¡bajo qué condiciones! — en poema de quien — todavía - percibe, que está atento a lo que aparece, que pregunta y habla a eso que aparece. Se hace diálogo; a menudo es un diálogo desesperado. ${ }^{10}$

Un diálogo desesperado (o no siempre esperanzado), que atesora aquello que puede todavía cuidar de la menguante humanidad que, en palabras de Levinas "adorna la tierra". ${ }^{11} \mathrm{El}$ filósofo —que toma distancia del pensamiento dialógico de Buber por ejemplo - pone el énfasis en el calificativo "desesperado" más que en el sustantivo "diálogo". Este diálogo desesperado es testimonio de la atención debida al otro, que se sabe siempre en falta, escucha tardía. El diálogo-desesperado se traza en una línea imaginaria que va de quien profiere el poema hacia ese Otro inasible — añoranza de un tú asequible- incesante curva que atraviesa los polos una y otra vez, sin arraigarse, sin tener lugar, siempre diferida, diferente, utópica. Esta línea es el Meridiano que el poeta dice encontrar "sobre un mapa para niños"12 (tal vez en un nivel pre-temático que resuena en infans, sobrevolando a la vez tropos y trópicos - Tropen). El lenguaje pre-temático en el encuentro con el Otro es lo que Levinas llamará el Decir, que es escucha previa a lo Dicho, afección corporal, estremecimiento provocado por la solicitación. El poema no es comunicación de un mensaje, es respuesta y atenta escucha.

\footnotetext{
${ }^{10}$ Celan, 507.

${ }^{11}$ Levinas, De otro modo que ser, 266.

12 Celan, 509.
} 
Encuentro lo que une y lo que lleva al encuentro como el poema.

Encuentro algo — como el lenguaje — inmaterial, pero terrenal, terrestre, algo circular, que vuelve sobre sí mismo a través de ambos polos y a la vez atraviesa — cosa graciosa— incluso los tropos: encuentro... un Meridiano. ${ }^{13}$

\section{La atención: un imperativo meridiano}

Si Kafka no llegó a rezar, cosa que no sabemos, hizo el uso más elevado de esa 'plegaria natural del alma' de Malebranche: la atención. En ella incluyó, como los santos en sus plegarias, a todas las criaturas. ${ }^{14}$

La atención, según Malebranche es una "plegaria natural del alma". Benjamin la vislumbró como cualidad de Kafka con relación a todas las criaturas, especialmente las "invisibilizadas". Según Levinas la atención al otro es (al igual que la plegaria) "receptividad extrema", y aun, "extrema donación": movimiento intenso en dos direcciones, relación con una exterioridad imperativa y abismal. Podríamos comparar este movimiento con otra metáfora levinasiana del lenguaje: la respiración, que es la relación con algo otro que se da como recepción y donación continuas. Palabra dada, en ambos sentidos: compromiso proferido, pero ante todo, es la escucha, testigo de la vergüenza de la palabra proferida que se sabe usurpadora ante el clamor silenciado del otro. El filósofo lituano lee la poesía de Celan en clave de atención que es descrita bajo la imagen de la "plena luz", meridiana:

(...) attention -mode de conscience sans distraction, c'est-àdire sans pouvoir d'évasion par d'obscurs souterrains; pleine

${ }^{13}$ Celan, 510 .

${ }^{14}$ Benjamin, "Franz Kafka", 156-157. Celan lo cita en "El Meridiano", 507. 
lumière projetée non pour voir les idées, mais pour interdire la dérobade; sens premier de l'insomnie qu'est la conscience —rectitude de la responsabilité avant tout apparoir de formes, d'images, de choses. ${ }^{15}$

El Meridiano, ya no sólo es esa línea imaginaria, inespacial, que une incesantemente en un movimiento sin retorno los polos, sino que también es el mediodía, sin un atisbo de sombra. Es la imposibilidad de evadirse de una responsabilidad que interpela - siempre de manera intempestiva - revelando la intemperie como ineludible condición del sujeto que se descubre insomne. Violencia del poema que invade el somnoliento refugio de la sombra con la luz enceguecedora del mediodía. El poema - después de Auschwitz-16 impide ver con claridad, encandila y ahonda la perplejidad, pero no lo hace de manera estetizante: la atención que demanda, solicita al lector, lo estremece. A veces lo hace deliberadamente, en segunda persona, como el poema que abre el testimonio de Primo Levi "Si esto es un hombre". Otras veces lo hace de manera tal que pone de manifiesto la vulnerabilidad del yo en una lengua desgarrada (tal es el alemán de Celan, y también el de Kafka).

La claridad meridiana enceguece, y a falta de competencia visual, se aguzan los oídos, se oyen los gritos, se escuchan los llamados. La injusticia resuena por doquier: allí donde los ojos ya no pueden ver, se impone lo invisible-intolerable mencionado por Jabès. En la misma carta de Benjamin a Scholem, a propósito de esa capacidad kafkiana de percibir "lo venidero sin percibir el presente", el autor comenta que "Kafka escu-

\footnotetext{
15 Levinas, "Paul Celan”: “(...) atención —modo de conciencia sin distracción, esto es, sin poder de evasión por obscuros subterfugios; plena luz proyectada no para ver las ideas, sino para prohibir la huida; sentido primero del insomnio que es la conciencia — rectitud de la responsabilidad antes que toda aparición de formas, de imágenes, de cosas" (traducción de S. R.).

${ }^{16} \mathrm{Y}$ a pesar de la sentencia de Adorno. El encuentro fracasado de Celan con Adorno es otra faceta de "su" 20 de enero.
} 
chaba atentamente la tradición, y quien aguza el oído, no ve". ${ }^{17}$ Nuevamente la "plegaria natural del alma", y la atención al pasado (la tradición —agregaríamos con Benjaminde los oprimidos $)^{18}$ permiten a quien está atento, abrirse para ser afectado por lo venidero. Para esto es necesario dejar en segundo plano al presente, cerrar los ojos ante la obscenidad espectacularizada, a fin de poder escuchar. La luz meridiana, entonces, además de poner al descubierto cualquier escondite, en el encandilamiento permite aguzar los oídos y percibir aquello que, por su intolerable diferencia, es invisibilizado a plena luz del día. La poesía meridiana tiene en común con la ética levinasiana la memoria del no-lugar, la luz excesiva que - en un proceso civilizatorio (e invisibilizatorio del otro)obliga a escuchar.

El poema, insistamos, es del orden del Decir levinasiano: pre-lógico y pre-temático; anterior al discurso razonado, no busca emitir un mensaje sino responder al llamado inmemorial como un "heme aquí". Tal como Platón lo menciona en el Fedro en torno a la "locura poética", el poema no es palabra propia, sino escucha proveniente de la inspiración, es palabra dada al otro, testimonio de desposesión. El poeta es una especie de médium que, al igual que el profeta, presta su boca para que Otro hable a través de él. Poesía, profecía: ambas son palabras inspiradas que acarician lo inaudito.

Según el poeta "el poema sería el lugar donde todos los tropos y metáforas nos invitan a reducirles al absurdo", 19 el filósofo entonces se pregunta si acaso Celan no sugiere a la poesía como "una modalidad inaudita del de otro modo que ser". ${ }^{20}$ Recordemos que para Levinas, de otro modo que ser indica la posibilidad de dar cuenta de la ética —que es relación al

\footnotetext{
17 Correspondencia, 247, 248.

${ }^{18} \mathrm{Cf}$. "Tesis de la filosofía de la historia".

${ }^{19}$ Celan, 507

${ }^{20}$ Levinas, "Paul Celan”, 56.
} 
otro - anterior a la ontología, esta última entendida como arraigo en el ser o afirmación del propio lugar. Si esta modalidad poética, tan inaudita como el de otro modo que ser, permite una aproximación al otro que disloca al "yo soy", da cuenta de un no-lugar, que recuerda al Meridiano "inmaterial, pero terrenal", y —agreguemos - infinito reenvío en una relación de pura exterioridad. El poema es entonces búsqueda del otro - en ambos sentidos - y, en palabras del poeta, se da en el secreto del encuentro ${ }^{21}$ que se ve sorprendido por una luz meridiana.

Ahora bien, recordemos que para Pascal el lugar bajo el sol es entendido como el principio de la usurpación. El sol meridiano sería el testigo que denuncia el no-lugar y anuncia el Meridiano. En palabras de Levinas:

Mais la surprise de cette aventure où le moi se dédie à l'autre dans le non-lieu, c'est le retour. Non pas à partir de la réponse de l'interpellé, mais de par la circularité de ce mouvement sans retour, de cette trajectoire parfaite, de ce méridien que, dans sa finalité sans fin, décrit le poème. ${ }^{22}$

\section{(Po)ética}

La tentación de escuchar la escritura que se desliza por la traducción es inevitable: al ser leída en voz alta en francés, la palabra "poétique" puede decir, "peau-éthique". Así, la poética nos sorprende transformada en una ética de la piel, de la corporalidad que, ante todo, define al sujeto vulnerable en la ética

${ }^{21}$ Celan "El Meridiano", 506.

${ }^{22}$ Levinas, "Paul Celan", 54. "Pero la sorpresa de esta aventura donde el yo se dedica al otro en el no-lugar es el retorno. No a partir de la respuesta del interpelado, sino por la circularidad de este movimiento sin retorno, de esta trayectoria perfecta, de este meridiano que, en su finalidad sin fin, describe el poema" (traducción de S. R.). 
levinasiana. Exposición a dos voces, "posición” que es éxodo duplicado: para Celan, del poema; para Levinas, del sujeto frágil. Palabra poética — si se nos permite — sugerida como "ética de la piel".

Usted dice: en el sufrimiento uno no puede hacer ya nada. Pero, ¿está usted seguro de que el sufrimiento se detiene en él mismo? Cuando se sufre por alguien, la vulnerabilidad es también sufrir para alguien. Se trata de esta transformación del 'por' en 'para', de esta substitución del 'por' por el 'para'. Si no se plantea esto, de inmediato uno se encuentra en un mundo de revancha, de guerra, de la afirmación prioritaria del yo. No discuto que de hecho siempre estemos en este mundo, pero es un mundo en el que estamos alterados. ${ }^{23}$

Dice Levinas que en este mundo estamos alterados. Indudablemente, en esta metafórica coordenada geográfica desde la que nos situamos para describir este mundo y sus dolores —el sur, "con el cielo abismal bajo los pies"-, la alteración adquiere otras dimensiones. Tanto el poeta como el filósofo, plantean el problema de la escucha del otro, cada uno a su manera subvierte el orden en su escritura, dando cuenta tanto de cierta alteración como prestando voz a la alteridad. No se trata de la buena disposición a escuchar: la luz del mediodía sorprende, nos prende en flagrancia, sin permitir dilaciones que se excusen en sesudas disquisiciones y pone al descubierto la usurpación. Tampoco se trata de desarrollar un sentido ausente, sino de dejar de reprimir la obstinada sensibilidad constitutiva del sujeto. Una sensibilidad que se manifiesta como atención, que da cuenta de la vulnerabilidad entendida — desde esta perspectiva invertida- como sufrimiento para y no por. Es decir, que sufrir para alguien obliga a re-significar la subjetividad que, al modo de Atlas, carga con la responsabilidad del

${ }^{23} C f$. Levinas, De Dios que viene a la idea, 144. 
sufrimiento del otro, no limitándose a condolerse por el padecimiento causado por otro. Es la perspectiva de una generosidad nada altruista, que se sabe usurpadora desde tiempos inmemoriales. En términos de ética: heteronomía.

Bajo el sol del mediodía, la única posición que se confiesa usurpadora es la exposición: posición que se abre a la exterioridad, en el caso de Levinas es la vulnerabilidad extrema frente al otro que solicita, esto es, hace temblar al yo. En palabras del poeta: La poésie ne s'impose plus, elle s'expose. ${ }^{24}$

Para el poeta sería un "cambio de aliento"; para el filósofo, es situarse en la perspectiva del de otro modo que ser. Propuestas inauditas ambas, que tienen que ver — reiteramos - con la intolerable invisibilidad. Lenguas desgarradas: el alemán del poeta rumano, el francés del filósofo lituano, son lenguas que vehiculan de diversos modos las cenizas de Auschwitz. En las diversas versiones "meridionales" del español resuenan los repetidos genocidios que pretendían ex nihilo fundar un "nuevo mundo", asimismo, repican los nombres de los desaparecidos de tantas dictaduras recientes, pero también el silencio de las anónimas muertes cotidianas en la miseria. Las (contra)palabras lanzadas dan cuenta de los estados alterados, son como pisadas que se saben profanadoras de cementerios clandestinos. Hablamos de heteronomías, en plural, porque es la escucha de diversas voces, torre de Babel — horizontal ${ }^{25}$ donde resuena el dolor de los vencidos.

Celan — como es sabido - es el poeta que demuestra que la poesía "después de Auschwitz" es otra: lejos del canto de las sirenas, el poema es una mano tendida, testimonio de las miserias de una "civilización" construida sobre el cadáver del Otro. El poema anuncia el Meridiano que prefigura el mediodía de la ética heterónoma, infinita solicitación del otro. La poesía

\footnotetext{
24 Celan, "El Meridiano", 493 ("La poesía ya no se impone, se expone").

25 Tomo la imagen de Joseph Roth, El Anticristo, 24.
} 
de Celan logra cabalmente la substitución del "por" por el "para" exigida por la ética de Levinas: en lugar de clamar por causa del dolor infligido por el otro, escribe para otro. El poeta sabe que su palabra es prestada: por eso escribe precisamente en alemán, para interrogarlo desde sus entrañas, para hacerle confesar su extranjería en la explosión de sentidos, en el vértigo de los significantes. En fin, para testimoniar poéticamente - desde la lengua de Heidegger - acerca de "la usurpación de toda la tierra". La ética heterónoma se revela como acto, deviene poética.

Sólo manos verdaderas escriben poemas verdaderos. No veo ninguna diferencia de principio entre el apretón de manos y el poema. $^{26}$

\section{Referencias}

Benjamin, Walter, "Franz Kafka", en Iluminaciones IV, Madrid, Taurus, 1999, pp. 135-161.

— "Tesis de la filosofía de la historia", en Angelus Novus, Barcelona, Edhasa, 1971, pp. 75-89.

- y Gershom Scholem, Correspondencia 1933-1940, Madrid, Taurus, 1987.

Celan, Paul, "El Meridiano" [1960], Obras completas, Madrid, Trotta, 1999, pp. 499-510.

- "Discurso con motivo de la concesión del premio de literatura de la ciudad libre hanseática de Bremen" [1958], Obras completas, Madrid, Trotta, 1999, pp. 497-498.

— "Carta a Hans Bender" [ 1960], Obras completas, Madrid, Trotta, 1999, pp. 489-490.

Gutiérrez Girardot, Rafael, "Poesía del silencio", Quimera, 191, mayo 2000, 18-26.

${ }^{26}$ Celan, “Carta a Hans Bender”, 489. 
JABÈs, Edmond, Le Parcours, Paris, Gallimard, 1985.

Levinas, Emmanuel, De otro modo que ser o más allá de esencia (1974), Salamanca, Sígueme, 1997.

- "Paul Celan", en Noms propres, Montpellier, Fata Morgana, 1976, pp. 49-56.

- De Dios que viene a la idea, Madrid, Caparrós, 1995.

Rотн, Joseph, El Anticristo, Barcelona, Península, 2002. 